\title{
Stress-induced Activation of Neuronal Activity and Corticotropin-releasing Factor Gene Expression in the Paraventricular Nucleus Is Modulated by Glucocorticoids in Rats
}

Toshihiro Imaki, Wang Xiao-Quan, Tamotsu Shibasaki, Konagi Yamada, Shoko Harada, Naoko Chikada, Mitsuhide Naruse, and Hiroshi Demura

Department of Medicine, Tokyo Women's Medical College, Tokyo 162, Japan

\begin{abstract}
Intronic in situ hybridization methodology provides a means of determining the rate of gene transcription under basal and stimulated conditions. In the present study, we have used intronic in situ hybridization to the corticotropin-releasing factor (CRF) gene to measure hypothalamic CRF gene transcription after stress as well as its modulation by glucocorticoids. Using this and conventional exonic in situ hybridization we examined the time course of changes in c-fos mRNA, and CRF heteronuclear RNA (hnRNA) and mRNA concentrations in the paraventricular nucleus (PVN) of male Wistar rats after restraint stress. In addition, we determined the effects of adrenalectomy and dexamethasone administration on c-fos and CRF gene expression in the PVN. Restraint stress induced a rapid induction (within 5 min) of c-fos mRNA and CRF hnRNA expression in the PVN. Both RNA concentrations peaked at 30 min then decreased and were undetectable $2 \mathrm{~h}$ after stress onset. In contrast, the concentration of CRF mRNA increased gradually and a significant elevation was first detected 60 min after the beginning of stress. Adrenalectomy augmented and dexamethasone pretreatment inhibited c-fos mRNA, CRF hnRNA, and mRNA induction after stress. The data suggest that stress-induced activation of neurons, CRF gene transcription, and CRF synthesis in the PVN are modulated by glucocorticoids. (J. Clin. Invest. 1995. 96:231-238.) Key words: heteronuclear RNA - adrenalectomy - gene transcription • in situ hybridization
\end{abstract}

\section{Introduction}

The 41-residue peptide corticotropin-releasing factor $(\mathrm{CRF})^{1}$ is known to be the principal hypophysiotropic factor stimulating stress-induced ACTH secretion (1-3). CRF mRNA and pep-

Address correspondence to Toshihiro Imaki, Institute of Clinical Endocrinology, Department of Medicine, Tokyo Women's Medical College, 8-1 Kawada-Cho, Shinjuku, Tokyo 162, Japan. Phone: 81-3-3353-8111 ext. 39223; FAX: 81-3-3357-6475.

Received for publication 12 April 1994 and accepted in revised form 2 March 1995.

1. Abbreviations used in this paper: ADX, adrenalectomy; CRF, corticotropin-releasing factor; hnRNA, heteronuclear RNA; PVN, paraventricular nucleus; ROD, relative optical density.

J. Clin. Invest.

(C) The American Society for Clinical Investigation, Inc.

0021-9738/95/07/0231/08 \$2.00

Volume 96, July 1995, 231-238 tide expression in parvocellular neurosecretory neurons is negatively regulated by glucocorticoids (4-6) and positively regulated by stress (6-9). Although many in vitro studies have examined the role of glucocorticoids on CRF gene transcription and mRNA concentrations (10-12), whole animal studies are important to establish the overall integrated hypothalamo-pituitary-adrenal (HPA) axis response to glucocorticoids. Indeed, the effect of stress on the transcriptional regulation of CRF gene is presently unknown, although observations that hypothalamic CRF mRNA concentrations are increased after stressful stimulations, such as hypertonic saline injection (7), footshock stress (6), streptococcal cell-wall-induced arthritis (8), restraint stress (9), and cold stress (9), have suggested that stress activates CRF gene transcription. However, posttranscriptional mechanisms including RNA splicing, stability of heteronuclear RNA (hnRNA) and/or mRNA, and mRNA transport from the nucleus represent additional or alternate mechanisms for the control of eukaryote gene expression (13). In addition, cytoplasmic mRNA appears to be regulated by degradation (e.g., poly-A tail length) (14-16). Stimulus-induced changes in mRNA concentrations are thus difficult to interpret.

In situ hybridization of cellular mRNAs provides a means of quantifying and localizing of gene expression in individual neurons. However, due to the relatively slow time course of changes in cytoplasmic mRNA concentrations and to their large pool, rapid alterations after stimulation have not been detected. In most cases, only 1.5- to 2-fold increases in CRF mRNA concentrations have been detected several hours after stress (79, 17). Semiquantitative in situ hybridization for mRNA is therefore particularly well suited to studies of long-term mRNA regulation rather than rapid changes during physiological or pharmacological challenges. Although the activity of neurons and secretory changes observed after stress are abrupt, the dynamic response of paraventricular nucleus (PVN) neurons to stimulation is less well understood. Given its rapid processing and turnover rate, the concentration of hnRNA (primary transcripts), should reflect the rate of gene transcription. Eukaryotic hnRNAs transcribed by RNA polymerase II are usually rapidly processed to mature mRNAs in the nucleus, which appear in the cytoplasm within 15 to $30 \mathrm{~min}$ after transcriptional activation $(18,19)$. Intronic in situ hybridization has been used to detect rapid alterations in proopiomelanocortin $(20,21)$ and vasopressin gene transcription $(22,23)$ within individual nuclei of pituitary cells and hypothalamic neurons. In both cases, the detected alterations accurately reflected proopiomelanocortin and vasopressin transcriptional activity as determined by in vitro nuclear run-on transcription assays. Using probes directed against an intronic sequence of the CRF gene, Herman et al. (24), have recently demonstrated that CRF hnRNA levels rapidly and markedly increased after acute glucocorticoid withdrawal induced by metyrapone administration. One of the poten- 
tial problems of intronic in situ hybridization is that splicing of introns from multiple-intron genes may occur at different rates, resulting in relatively stable intermediates. Since the CRF gene possesses only a single intron (25), detection of changes in CRF hnRNA can be interpreted as changes in gene transcription.

Expression of the protooncogene c-fos has been validated as a cellular marker of neural systems activated by a variety of extracellular stimuli (26-28). c-fos has been particularly useful in examining the activation of neuroendocrine responses to stressful stimuli $(17,29,30)$. Thus, the combination of in situ analysis of c-fos mRNA and hnRNA expression in the same animals provides a means of detecting rapid stimulus-induced changes in gene transcription, i.e., stimulus transcription coupling, in individual neurons in vivo.

In this paper, using semiquantitative in situ hybridization with probes complementary to a potion of an intronic and exonic sequence of the rat CRF gene combined with data on c-fos expression as a metabolic marker of cellular activation, we studied the time course of changes in c-fos, CRF hnRNA and mRNA expression in the PVN after acute restraint stress, and then examined the effect of glucocorticoids on stimulus transcription coupling in PVN neurons in vivo.

\section{Methods}

Adult male Wistar albino rats (200-250 grams) were used in all experiments. The animals were housed three per cage in a room with controlled temperature and a fixed lighting schedule (lights on from 8:00 a.m. to 8:00 p.m). Food and water were given ad lib. Six rats per group were examined. All of following experimental protocols were approved by the animal committee of the Tokyo Women's Medical College, Tokyo, Japan.

Time course of expression of c-fos mRNA, CRF hnRNA, and mRNA after stress. The rats were placed in a restraint cage (Natume, Tokyo, Japan) for $30 \mathrm{~min}$ and then killed before and 5, 10, 15, 30, 60, 120 min after the beginning of stress. For measuring plasma ACTH and corticosterone, rats in a separate group were decapitated at the same intervals after the beginning of stress. Trunk blood was collected on ice in plastic tubes containing EDTA, centrifuged $(3,000 \mathrm{rpm}$ for $20 \mathrm{~min}$ at $4^{\circ} \mathrm{C}$ ), and the plasma was frozen at $-20^{\circ} \mathrm{C}$ until assayed.

Effect of adrenalectomy ( $A D X)$ on c-fos mRNA, CRF hnRNA, and mRNA after stress. ADX was performed through a dorsal incision under sodium pentobarbital ( $50 \mathrm{mg} / \mathrm{kg}$, intraperitoneally) anesthesia. On return to their cages, the animals had free access to normal saline. $1 \mathrm{wk}$ after the operation, the rats were exposed to restraint stress for $30 \mathrm{~min}$ and killed at the end of the stress. Sham operation was performed by manipulating the animal in the same manner but without removing the adrenal gland, and these animals were used as controls. ADX and sham rats were also killed without stress (nonstressed group). To determine the efficacy of ADX, $2 \mathrm{ml}$ of blood was collected through cardiac puncture for measuring plasma ACTH and corticosterone, at the time of transcardiac perfusion.

Effect of dexamethasone on c-fos mRNA, CRF hnRNA, and mRNA expression after stress. $2 \mathrm{mg} / \mathrm{kg}$ dexamethasone sodium phosphate (Decadron, dissolved in sterile water, $\mathrm{pH} 7.0-8.5$, osmolarity is as same as normal saline; Banyu, Japan) or normal saline was injected intraperitoneally to the rats $1 \mathrm{~h}$ before the 30-min restraint stress, and the rats were then killed. The rats with either dexamethasone or saline injection without stress were also included in this experiment. They were perfused $90 \mathrm{~min}$ after saline or dexamethasone injection. The blood was collected in a same manner as above to determine plasma levels of ACTH and corticosterone.

\section{In situ hybridization}

Rats were deeply anesthetized with pentobarbital and perfused with icecold $4 \%$ paraformaldehyde in a $\mathrm{pH} 9.50 .1 \mathrm{M}$ borate buffer (31). The brains were placed for $2 \mathrm{~d}$ at $4^{\circ} \mathrm{C}$ in fixative containing $10 \%$ sucrose. Frozen sections ( 20 or $30 \mu \mathrm{m}$ ) were cut on a sliding microtome, mounted onto gelatin- and poly L-lysine coated slides, and air-dried.

Hybridization was performed as previously described (31), with minor modifications. Before hybridization, sections were dried overnight under vacuum, digested with proteinase $\mathrm{K}\left(10 \mu \mathrm{g} / \mathrm{ml}, 37^{\circ} \mathrm{C}, 30 \mathrm{~min}\right)$, acetylated, and dehydrated. After vacuum drying, $90 \mu \mathrm{l}$ of the hybridization mixture $\left(10^{6} \mathrm{cpm} / \mathrm{ml}\right.$, with $10 \mathrm{mM}$ DTT $)$ was spotted onto each slide, sealed under a coverslip, and incubated at $60^{\circ} \mathrm{C}$ for $2 \mathrm{~d}$. The coverslips were then removed and the slides were rinsed in $4 \times$ SSC (1 SSC; $15 \mathrm{mM}$ trisodium citrate buffer, $\mathrm{pH} 7.0 / 0.15 \mathrm{M} \mathrm{NaCl}$ ) at room temperature. The sections were digested with RNase A $\left(20 \mu \mathrm{g} / \mathrm{ml}, 37^{\circ} \mathrm{C}\right.$, $30 \mathrm{~min}$ ), washed in $0.1 \times \mathrm{SSC}$ for $30 \mathrm{~min}$ at $65^{\circ} \mathrm{C}$. These sections were exposed to x-ray film at $4^{\circ} \mathrm{C}$ for 7-21 d, then dipped in NTB2 nuclear emulsion (1:1 with water; Eastman Kodak Co., Rochester, NY), exposed for 7 or $42 \mathrm{~d}$ and developed. The slides were counterstained with thionine. An adjoining series of sections was stained with thionine to provide better cytoarchitectonic definition for analysis. All samples from a single experiment were run in a single assay.

\section{Probe labeling}

A pGEM-4 plasmid containing the rat CRF cDNA (1.2 kb, gift from Dr. K. Mayo, Northwestern University, Evanston, IL) was linearized with HindIII. The EcoRI fragment of rat c-fos $\mathrm{c}$-DNA $(2.0 \mathrm{~kb}$, gift from Dr. I. Verma, Salk Institute, San Diego, CA) was subcloned into pBluescript SK-I (Stratagene Inc., La Jolla, CA) and linearized with BamHI. The CRF intronic probe was a 530-bp PVUII fragment localized entirely within the single intronic of the rat CRF gene. The PVUII fragment was subcloned into pSP 72 and linearized with EcoRI. Radioactive antisense cRNA copies were synthesized by incubation of 36 $\mathrm{mM}$ Tris, $\mathrm{pH} 7.5,0.1 \mu \mathrm{g}$ linearized plasmid in $6 \mathrm{mM} \mathrm{MgCl} 2,2 \mathrm{mM}$ spermidine, $8 \mathrm{mM}$ DTT, $25 \mathrm{mM}$ ATP/GTP/CTP, $5 \mathrm{mM}$ unlabeled UTP, $\left[\alpha-{ }^{35}\right.$ S ]-UTP, 1 U RNAsin (Promega Corp., Madison, WI), and T7 polymerase (Promega Corp.) for c-fos and SP-6 for CRF intronic and exonic probes, for $60 \mathrm{~min}$ at $37^{\circ} \mathrm{C}$. Sense probes for the CRF intronic sequence were made using the $\mathrm{T} 7$ transcription system. All probes were purified on resin columns (Nensorb 20; NEN Research Products, Boston, MA). The specific activity of each probe was $\sim 1.0 \times 10^{8}$ $\mathrm{dpm} / \mu \mathrm{l}$.

\section{Determination of plasma ACTH and corticosterone}

Plasma ACTH and corticosterone were determined by immunoradiometric assay (IRMA; ACTH-II IRMA kit; Mitsubishi Yuka Medical Co., Tokyo, Japan), and RIA (ImmuChem Double Antibody ${ }^{125}$ I corticosterone RIA kit; ICN Biomedicals. Inc. Costa Mesa, CA), respectively. According to the manufacturer, typical interassay variation was around $4-7 \%$, and typical intraassay variation was $\sim 7 \%$.

Data analysis. The density of c-fos mRNA, CRF hnRNA, and CRF mRNAs on autoradiograms was semiquantified using an MCID image analysis system (Imaging Research, Inc., St. Catherines, Canada) (32). This system digitizes the continuous range of image gray shades into 256 discrete gray levels, in which the lower values are given to the darker group. The levels obtained were converted to relative optical densities (ROD) using the formula: ROD $=\log _{10}(256 /$ levels $)$. The optical densities of areas of interest were measured bilaterally on at least two sections from each subject. The ROD within the window was measured and the background was assessed by measuring ROD with the window placed over another area of the brain in which no c-fos, CRF mRNA, or CRF hnRNA expression was detected. Values are presented as the mean \pm SEM. Statistical analysis was performed by analysis of variance followed by Duncan's multiple range test. A $P<0.05$ was considered significant.

\section{Results}

The localization of hybridization signals for intronic and exonic CRF probes 30 min after stress is shown in Fig. 1. Autoradio- 

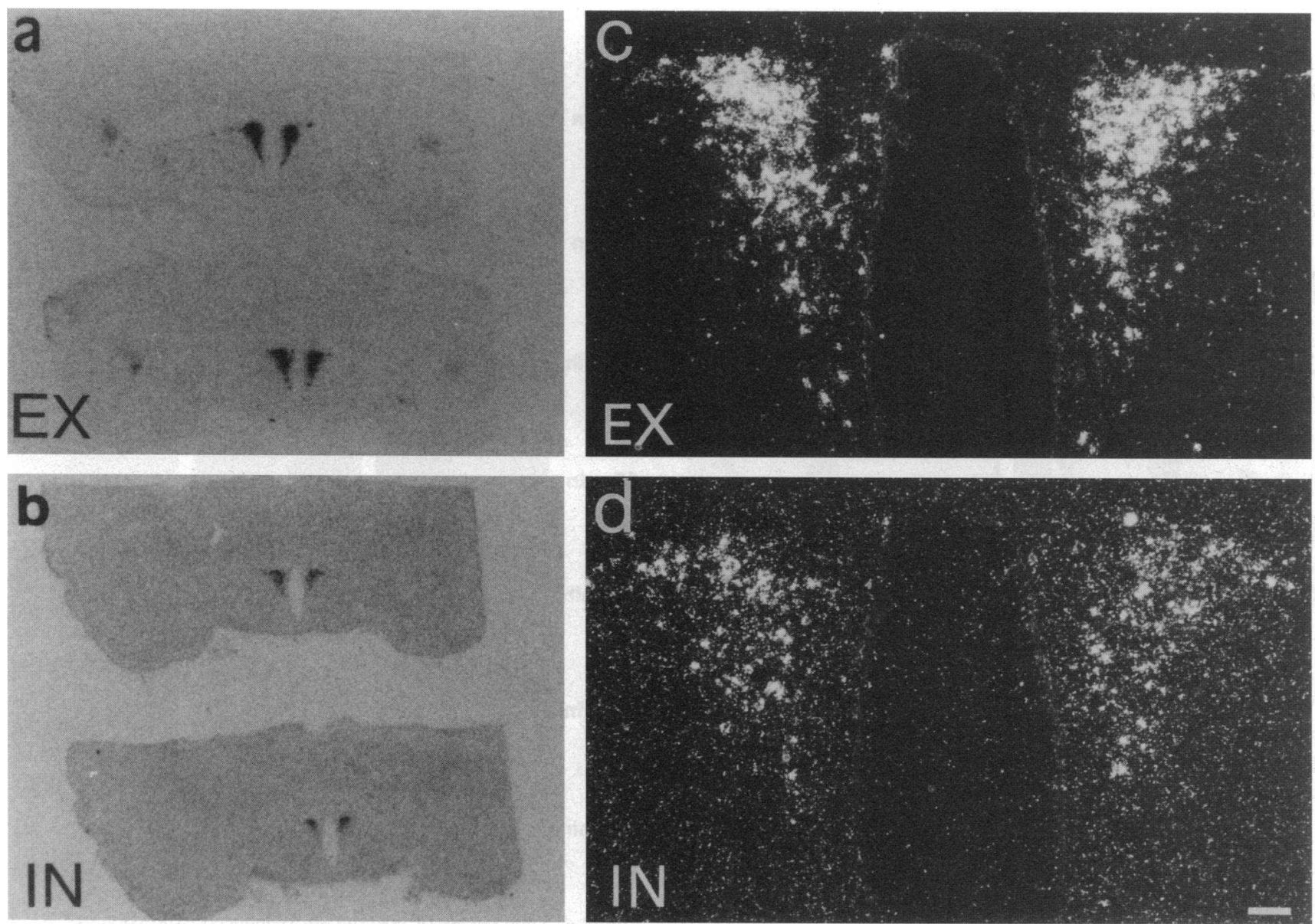

Figure 1. Comparison of hybridization signals for CRF mRNA (top) and CRF hnRNA (bottom) in the hypothalamus ( $\mathrm{x}$-ray film; left) and darkfield photomicrographs (right) in the rats $30 \mathrm{~min}$ after the onset of stress. Note that both CRF mRNA and hnRNA are primarily distributed over the parvocellular division of the PVN. Exposure time was 5 (CRF mRNA) and $18 \mathrm{~d}$ (CRF hnRNA) on $\mathrm{x}$-ray films, and 10 (CRF mRNA) and $35 \mathrm{~d}$ (CRF hnRNA) on emulsion-dipped slides. Bar $=100 \mu \mathrm{m}$.

grams showed that both CRF mRNA and hnRNA were distributed predominantly in the parvocellular division of the PVN. Considerably longer exposure times ( $18 \mathrm{~d}$ ) were required with CRF intronic probes for detectable autoradiographic signals on $x$-ray films than with the CRF exonic probes $(5 \mathrm{~d})$. Neither sense-stranded controls nor sections preincubated with RNase A ( $10 \mu \mathrm{g} / \mathrm{ml}$ at $37^{\circ} \mathrm{C}$ for $\left.30 \mathrm{~min}\right)$ before hybridization with the antisense CRF intronic probe showed any positive signal (Fig. $2, b$ and $c$ ), demonstrating the specificity of the in situ hybrid- ization probe used. High power views of single PVN cells expressing CRF mRNA and hnRNA are shown in Fig. 3. The majority of silver grains were localized over the cytoplasm when sections through the hypothalamus were hybridized with CRF exonic probes. In contrast, silver grains were specifically localized over the nuclei of neurons in the PVN after hybridization with the CRF intronic probe. Thus, the autoradiographic signal obtained with CRF intronic probes appears to result from specific hybridization to primary transcripts of the CRF gene a

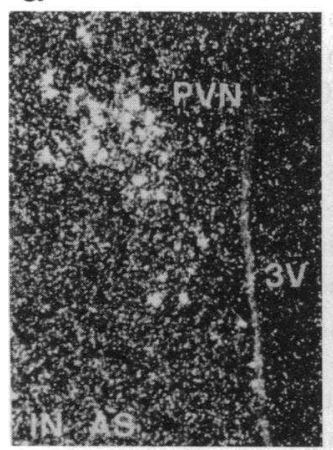

b

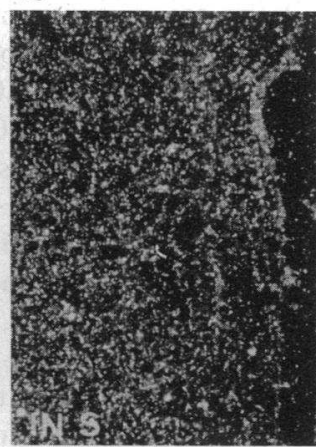

C

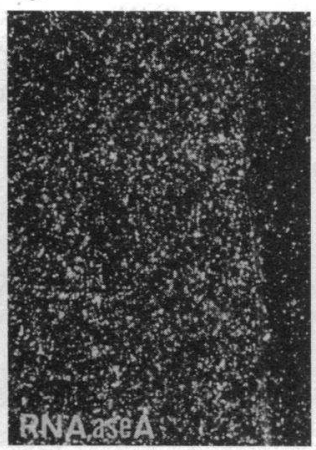

d

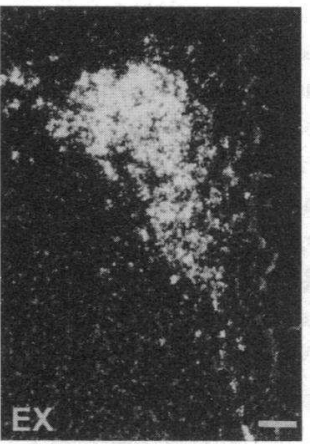

Figure 2. Darkfield photomicrographs showing silver grains over PVN. (a) Section hybridized with antisense intronic probe. $(b)$ Section hybridized with a sense strand intronic probe. (c) Section hybridized with the intronic probe after incubation with RNase A. (d) Section hybridized with an exonic probe. $3 \mathrm{~V}$, third ventricle. Exposure time was $35 \mathrm{~d}$ (intronic probe, $I N$ ) and $5 \mathrm{~d}$ (exonic probe, $E X) . B a r=100 \mu \mathrm{m}$. 

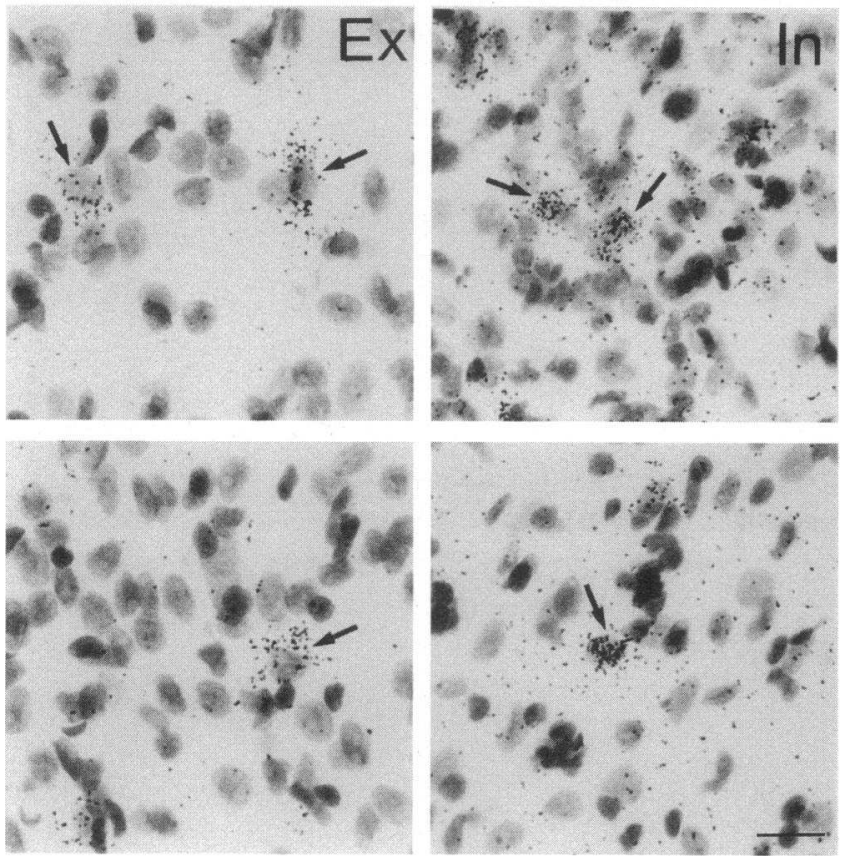

Figure 3. High-power field magnification of parvocellular neurons of the PVN hybridized with the exonic ( $E x)$ probe (left) or with the intronic (In) probe (right). Bar $=25 \mu \mathrm{m}$.

localized within the nuclei of PVN neurons expressing the CRF gene.

CRF hnRNA and c-fos mRNA showed rapid changes over a similar time course after stress. Only a few scattered cells in the PVN were labeled with CRF intronic and c-fos $\mathrm{cRNA}$ probes before stress (Fig. 4). However, as early as $5 \mathrm{~min}$ after restraint stress, increases in CRF hnRNA and c-fos mRNA concentrations were clearly visualized (Fig. 4). The intensity of the signal peaked at $30 \mathrm{~min}$, then declined and was virtually undetectable 120 min after stress onset (Fig. 4). CRF mRNA, which was constituently expressed in the PVN, remained unchanged during the first $30 \mathrm{~min}$ after stress, but increased at the $60 \mathrm{~min}$ time point (Fig. 4, right). Assay of plasma ACTH and corticosterone concentrations revealed a predictable time course of hormone changes in response to acute restraint stress. There was a significant overall effect of treatment on plasma ACTH and corticosterone levels after $5,10,15,30$, and $60 \mathrm{~min}$ of the onset of stress. Interestingly, densitometric analysis showed a quite similar time course changes in CRF hnRNA and c-fos mRNA concentrations and plasma ACTH and corticosterone in response to stress. CRF hnRNA and c-fos mRNA increased significantly at $5 \mathrm{~min}$ time point, reaching their peak values at the 30 min time point, after which the levels of both RNAs gradually declined, returning to basal levels by $120 \mathrm{~min}$ after the onset of stress (Fig. 5, ROD of CRF hnRNA at $30 \mathrm{~min}$ $0.049 \pm 0.011, P<0.0001$ vs those at $0 \mathrm{~min} ; \mathrm{ROD}$ of c-fos mRNA at $30 \mathrm{~min} 0.234 \pm 0.020, P<0.0001$ vs those at 0 $\mathrm{min}$ ). In contrast, cytoplasmic CRF mRNA concentrations were unchanged until 60 min after the onset of stress (Fig. 5). A significant increase in CRF mRNA was first detected 60 min after the beginning of stress (Fig. 5, ROD of CRF mRNA at $60 \mathrm{~min}, 0.148 \pm 0.015, P<0.05$ vs those at $0 \mathrm{~min}$ ).

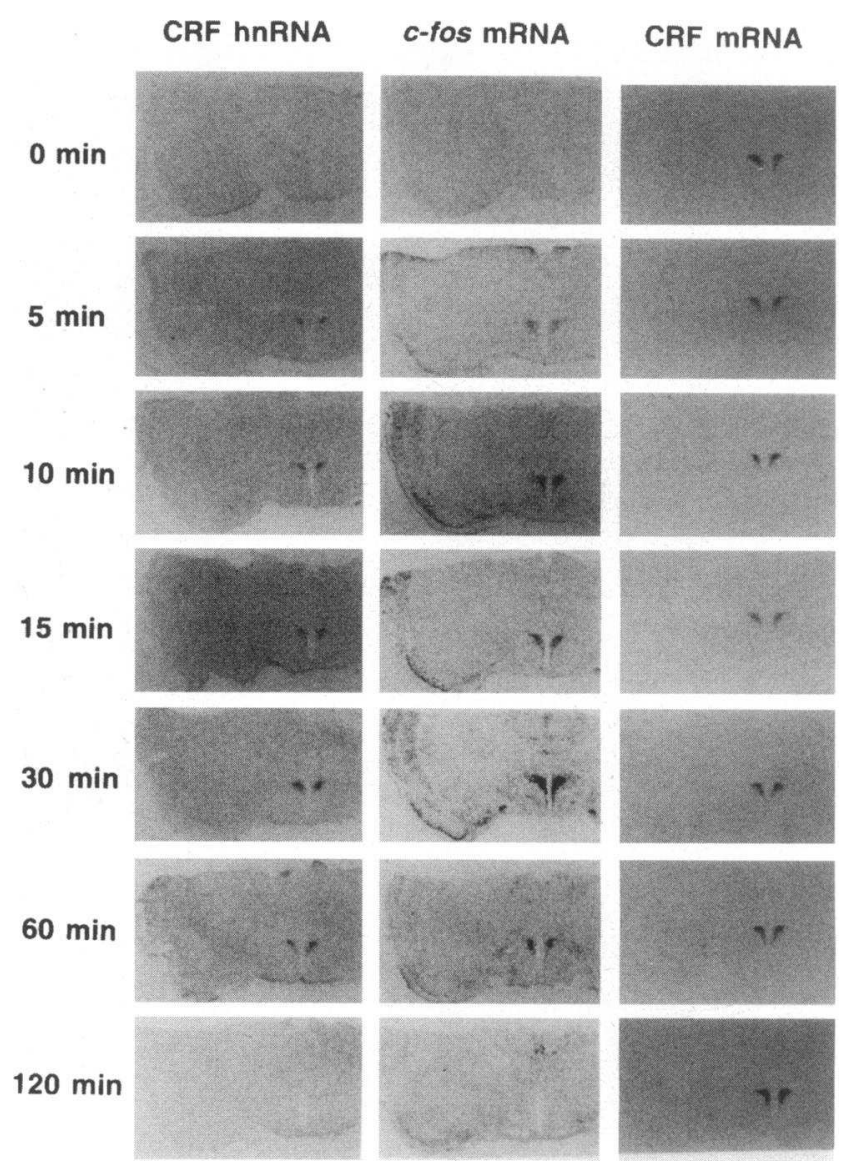

Figure 4. Time course of restraint stress-induced expression of CRF intronic (left), c-fos (middle), and CRF exonic RNA (right) in the PVN. Note the rapid induction of CRF hnRNA expression, quite similar to that of c-fos mRNA expression. In contrast, CRF mRNA showed a slow and gradual increase after stress. Exposure time was $3 \mathrm{~d}$ (c-fos and CRF mRNA) and $9 \mathrm{~d}$ (CRF hnRNA).

The effect of adrenalectomy on plasma levels of ACTH and corticosterone, and CRF hnRNA, c-fos, and CRF mRNA expression in the PVN are summarized in Fig. 6. ADX significantly increased both basal and stress-induced secretion of ACTH (Fig. 6, top ). In ADX animals, corticosterone was undetectable in both nonstressed and stressed groups. This confirmed the efficacy of the surgery. In nonstressed animals, c-fos mRNA and CRF hnRNA were virtually undetectable in the PVN in both sham-operated and ADX rats, while CRF mRNA was significantly increased 1 wk after ADX, when compared to sham animals (Fig. 6, bottom). CRF hnRNA and c-fos mRNA in the PVN of stressed rats were significantly augmented in ADX animals compared to the sham group (Fig. 6, ROD of CRF hnRNA: sham $0.021 \pm 0.005$, ADX $0.050 \pm 0.005, P<0.005$; ROD of c-fos mRNA: sham 0.128 \pm 0.021 , ADX 0.200 \pm 0.019 , $P<0.005)$. The CRF mRNA level was also significantly higher in ADX animal than that in the sham group. CRF mRNA did not significantly increase at the 30 -min time point after stress in either ADX or sham rats as described in Fig. 5 (Fig. 6, ROD of CRF mRNA: sham $0.118 \pm 0.017$, ADX $0.237 \pm 0.013, P$ $<0.005)$.

In the next series of experiments, the effect of dexamethasone was examined. Dexamethasone injection significantly de- 


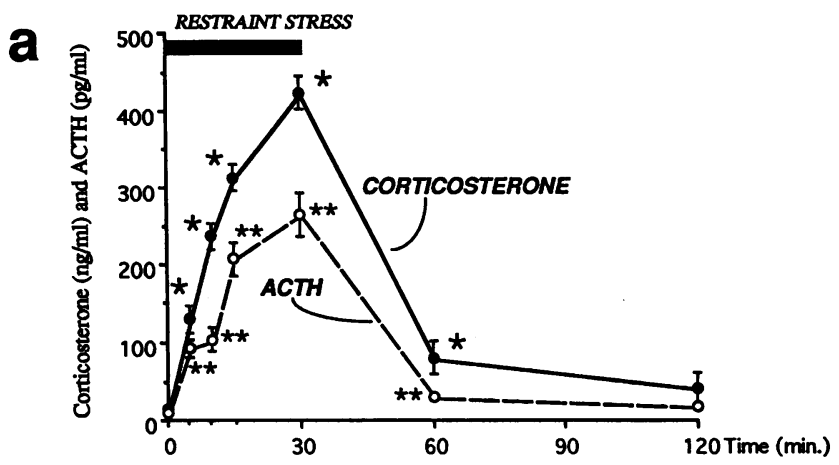

b

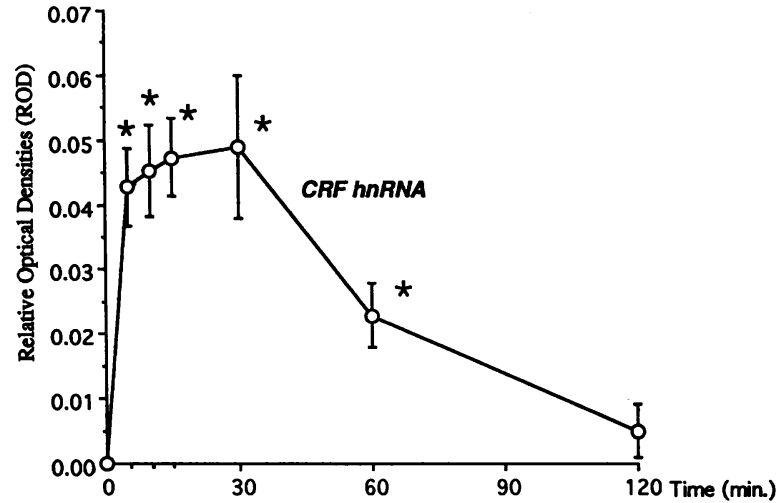

C

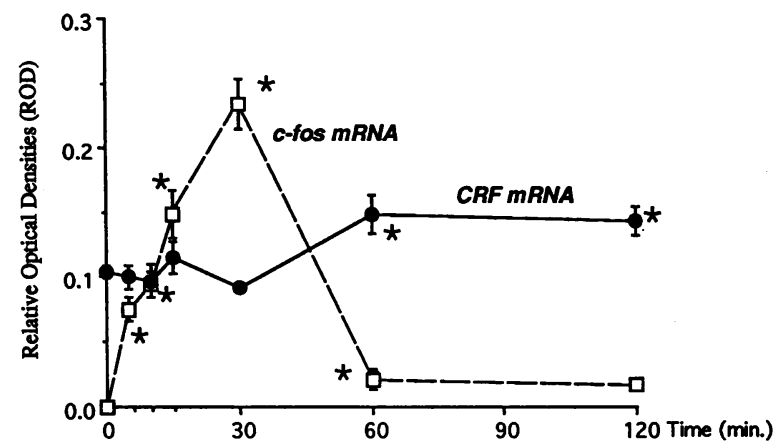

Figure 5. Line graphs showing the time course of changes in plasma ACTH and corticosterone levels ( $a$ ), expression of CRF hnRNA (b), and expressions of $c$-fos mRNA and CRF mRNA (c) after restraint stress. Note that both c-fos mRNA and CRF hnRNA showed a time course of expression similar to changes in plasma ACTH and corticosterone in response to stress. Significant increases in both ACTH and corticosterone, as well as c-fos and CRF hnRNA were observed as early as $5 \mathrm{~min}$, while significant changes in CRF mRNA were first noted 60 min after the onset of stress. Each point is the mean \pm SEM of values obtained from six animals per group. ${ }^{*} P<0.05$ vs at 0 min.

creased basal ACTH and corticosterone secretion (Fig. 7, top). Basal CRF hnRNA was undetectable in nonstressed animals (Fig. 7, bottom). Basal c-fos mRNA was detectable in the saline-injected group, probably due to the mild stress of the procedure, and this was also inhibited by dexamethasone (Fig. 7). Basal CRF mRNA was slightly decreased by dexamethasone treatment, although this change was not statistically significant (Fig. 7). Restraint stress significantly increased both ACTH and corticosterone concentrations, as well as CRF hnRNA and c-fos mRNA levels in the PVN in the saline- and dexamethasone-injected groups. CRF mRNA was not significantly increased at 30-min time point after stress as described above.
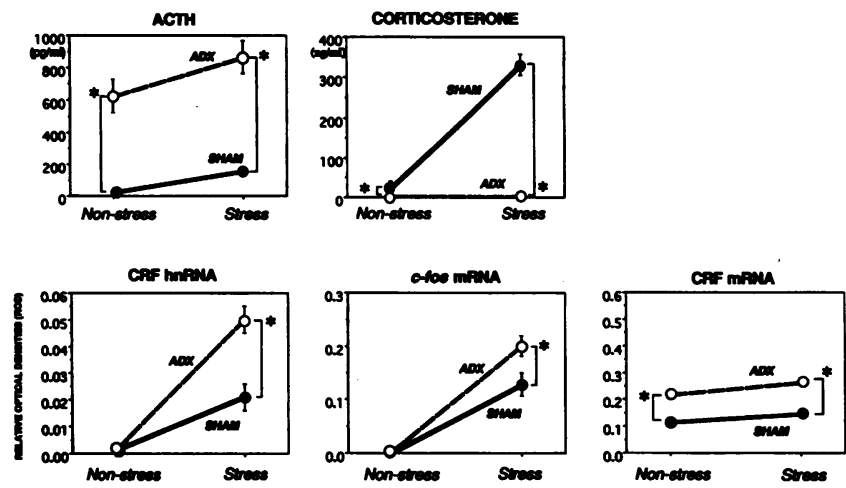

Figure 6. Effect of ADX on plasma ACTH and corticosterone levels (top), and CRF hnRNA, c-fos mRNA, and CRF mRNA expression in the PVN (bottom) in nonstressed and stressed ( 30 min after stress onset) animals. Results, expressed as ROD, are the mean \pm SEM of six animals for each group. ${ }^{*} P<0.005$ vs sham group. The plasma ACTH concentrations, and CRF hnRNA and c-fos mRNA levels were significantly higher in stressed animals than those in nonstressed animals $(P<0.005)$ in both ADX and sham groups. Plasma corticosterone level was significantly higher in the stressed group than in the nonstressed group in the sham-operated animals $(P<0.005)$. Plasma corticosterone was undetectable in ADX rats.

Dexamethasone injection significantly decreased ACTH and corticosterone levels (Fig. 7, top ), as well as CRF hnRNA, cfos mRNA, and CRF mRNA levels in the PVN of stressed animals, when compared to rats receiving saline injection (Fig. 7, bottom, ROD of CRF hnRNA: saline + stress $0.031 \pm 0.006$, dexamethasone + stress $0.021 \pm 0.005, P<0.005$; ROD of c-fos mRNA: saline + stress $0.270 \pm 0.023$, dexamethasone + stress $0.153 \pm 0.016, P<0.005$; ROD of CRF mRNA: saline + stress $0.227 \pm 0.014$, dexamethasone + stress $0.162 \pm 0.009$, $P<0.005)$.

\section{Discussion}

These studies indicate that CRF intronic probes can be used to detect and quantitiate CRF hnRNA within the brain. Localiza-
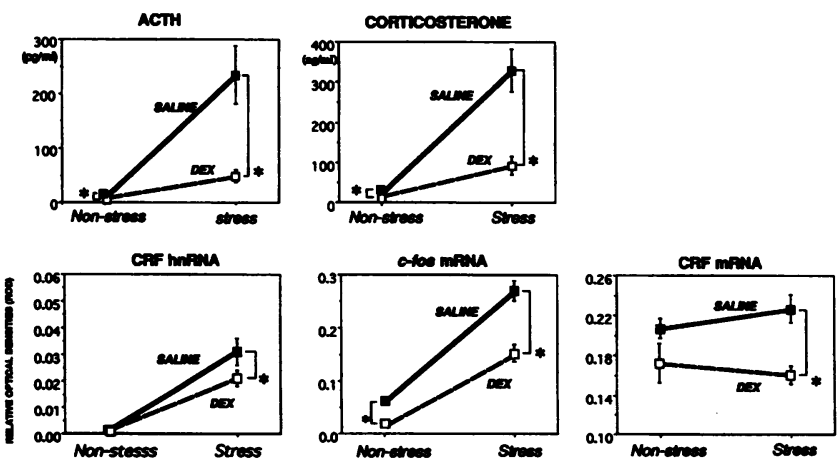

Figure 7. Effect of dexamethasone on plasma ACTH and corticosterone levels (top), and CRF hnRNA, c-fos mRNA, and CRF mRNA expression in the PVN (bottom) in nonstressed and stressed ( $30 \mathrm{~min}$ after stress onset) animals. Results, expressed as ROD, are the mean \pm SEM of six animals for each group. ${ }^{*} P<0.005$ vs saline-injected group. The plasma ACTH and corticosterone concentrations, and CRF hnRNA and c-fos mRNA levels were significantly higher in stressed animals than in nonstressed animals $(P<0.005)$. 
tion of CRF intron signals can be accurately localized to the nuclei of CRF-producing neurons, including the parvocellular subdivisions of the PVN, which are known to contain CRF peptide and mRNA. Sense-strand and RNase pretreated controls do not have any positive signal, demonstrating hybridization specificity. In addition, the specificity of hybridization was confirmed by the nuclear localization of the labeling as compared with the hybridization signal obtained using the exonic probe. The basal level of CRF hnRNA in the PVN was undetectable by our in situ analysis. However, expression was rapidly induced (within $5 \mathrm{~min}$ ) by restraint stress, reaching a peak at $30 \mathrm{~min}$. This induction was transient: CRF hnRNA was once again undetectable $120 \mathrm{~min}$ after stress. The rapid and transient induction of CRF primary transcripts allows analysis of rapid alterations in CRF gene transcription in response to stimuli in individual neurons in vivo. The increase in CRF gene transcription was inhibited by administration of glucocorticoids and stimulated by removal of glucocorticoids by ADX. To our knowledge, these data provide the first demonstration that CRF gene transcription in the PVN is up-regulated by stress and down-regulated by glucocorticoids.

Expression of the c-fos protooncogene is rapidly and temporally activated in a variety of mammalian cell types by a diverse set of stimuli (26). Specific electrical, sensory, noxious, and stressful stimuli have been reported to induce fos expression in discrete brain regions known to be neuroanatomical targets for such stimuli (26-30). Thus, c-fos mRNA and fos protein expression can be used for metabolic mapping at the cellular level. We have previously reported that early induction of cfos precedes increased expression of CRF mRNA in the PVN after stress (17). Interestingly, the time course of changes in CRF hnRNA expression in response to stress was quite similar to changes in c-fos mRNA expression. A significant induction in both CRF hnRNA and c-fos mRNA was transiently observed 5 min after the onset of stress, after which the levels of both RNAs peaked at the 30-min time point, then declined and almost disappeared by $2 \mathrm{~h}$. This may reflect rapid processing and turnover of the primary transcript in the nucleus such as that of proopiomelanocortin hnRNA, which has a half-life significantly less than $30 \mathrm{~min}(20)$. The rapid stimulus transcription coupling in PVN neurons in vivo may reflect the activation of second messenger pathways such as the cAMP pathway, which are involved in CRF gene transcription. This possibility is supported by the presence of a cAMP responsive element on the CRF gene (33). In contrast to CRF hnRNA, significant changes in CRF mRNA concentrations were not seen until $60 \mathrm{~min}$, consistent with previous studies showing a lag time of several hours between stress and changes in CRF mRNA levels $(7-9,17)$. The observed delay between transcriptional activation and changes in cytoplasmic mRNA levels probably reflect the large pool of CRF mRNA in PVN neurons. For this reason, in some instances, mRNA concentrations may be of limited value as indicators of rapid changes in gene expression. In situ hybridization using probes directed against an intronic sequence of the gene has the advantage of being able to detect rapid gene activation in response to stress. In addition, it can be used to resolve transcriptional activation within complex and heterogeneous regions of the brain.

The rapid changes in CRF gene transcription and c-fos expression were well correlated with the actual pituitary-adrenal responses; i.e., secretion of ACTH and corticosterone after stress. Thus, measurement of CRF hnRNA in combination with c-fos mRNA may provide a powerful means to detect transients in the hypothalamo-pituitary-adrenal axis. Indeed, ACTH and corticosterone responses are back to control levels by $60 \mathrm{~min}$, well before the end of fos protein synthesis and before the response of increased CRF mRNA. The observed changes in CRF gene transcription in response to stress could reflect a requirement to increase CRF stores to meet the demands of the next stimulus to the PVN neurons. In other words, the increase in CRF mRNA levels in the PVN after a single restraint may be an adaptive compensatory response. Similarly, immediate early genes, including c-fos, may in fact act as "third messengers" in response to stress and directly control the activity of target genes responsible for the biochemical and morphological changes that develop later in neuronal physiology.

The potent inhibitory effects of adrenal glucocorticoids on CRF biosynthesis and release from the hypothalamus have been well documented $(34,35)$, Acute administration of dexamethasone has been found to significantly inhibit CRF mRNA accumulation in the PVN after stress $(36,37)$. Dexamethasone also has been found to reduce CRF mRNA concentrations by $>90 \%$ in a human primary liver carcinoma cell line (NPLC) which endogenously expresses the CRF gene (12). Recently, the human CRF gene has been introduced into mouse anterior pituitary tumor cells (AtT-20) and stable transformants have been shown to express the human CRF gene in a fashion which is negatively regulated by glucocorticoids (10). Glucocorticoids appear to block the effects of the protein kinase-A pathway on CRF gene expression at the transcription level. However, the effect of glucocorticoids on CRF gene transcription in the PVN in vivo has not been addressed. In this study, we demonstrated using an intron-specific probe, that dexamethasone significantly inhibits the expression of CRF hnRNA and c-fos mRNA in the PVN in response to stress. Thus, glucocorticoids are capable of inhibiting stress-induced gene activation in PVN neurons including that of CRF. Glucocorticoids may directly inhibit CRF gene expression in the PVN as a result of the strong glucocorticoid receptor immunoreactivity present in the vast majority of parvocellular PVN neurons, including CRF immunoreactive neurons (38). However, indirect routes, such as those mediated via the hippocampus might be involved in glucocorticoid-induced CRF gene suppression. By contrast, dexamethasone inhibited CRF mRNA accumulation $30 \mathrm{~min}$ after stress. This reflects the late changes in CRF mRNA after the inhibition of stress-induced CRF gene transcription by dexamethasone.

Conversely, it has been reported that ADX is accompanied by large increases in CRF mRNA in the PVN and by significant elevations in the levels of hypothalamic CRF $(5,6)$. In the current study, we found that stress-induced alterations in both CRF hnRNA and c-fos expression were significantly increased in ADX rats compared to sham-operated animals. This indicates that ADX augments both stress-induced cellular activation and CRF gene transcription in the PVN. This is consistent with a previous report by Herman et al. (24), in which both CRF hnRNA and c-fos mRNA expression increased markedly 1530 min after metyrapone injection, a substance which inhibits the conversion of 11-deoxycorticosterone to corticosterone and, thereby, rapidly depletes glucocorticoids. The increases we observed in CRF hnRNA and c-fos mRNA levels in ADX rats were associated with an increase in cytoplasmic CRF mRNA levels in the PVN, as previously reported by others (39). Both CRF hnRNA and c-fos mRNA were undetectable in the PVN in nonstressed $A D X$ animals whose CRF production and release 
are thought to be increased. Although acute glucocorticoid removal has been reported to increase CRF hnRNA and c-fos mRNA (24), the induction of these RNAs appeared to be transient. Consistent with this interpretation, Bacon and Sawchenko did not find elevated level of c-fos in the PVN a week after ADX using a specific c-fos antisera (40).

Phorbol ester increases CRF mRNA levels in primary cultures of rat hypothalamic cells (41) as well as NPLC cells (42). The proximal 0.9-kb $5^{\prime}$ flanking the human CRF gene confer AP-1 inducibility to a CAT reporter in transient expression assays (43). In the absence of a clearly discernible perfect AP-1 site in this region, it has been suggested that the cAMP responsive element of the CRF promoter may elicit AP-1-like responses. Further upstream into the 5'-flanking region of human CRF gene, eight perfect consensus AP-1 binding sites have been detected (44). The functionality of these sites and their physiological role remain to be determined.

In summary, the current study demonstrates the regulation of CRF gene expression, CRF biosynthesis, and cellular activity by stress and glucocorticoids in the PVN. The use of an intronspecific probe allowed us to follow time-dependent changes in CRF primary transcripts in vivo in the PVN after stress, and demonstrated rapid alterations in CRF gene transcription coincident with activation of c-fos mRNA expression and followed by CRF mRNA accumulation in the PVN in response to stress. Exogenous administration of glucocorticoids down-regulated and adrenalectomy up-regulated neuronal activity and CRF gene transcription after stress in the PVN. Thus, glucocorticoids modulate cellular activity and CRF gene expression in PVN neurons during acute stress.

\section{Acknowledgments}

We thank Drs. K. Mayo (Northwestern University, Evanston, IL) and I. Verma (Salk Institute, San Diego, CA) for gifts of rat CRF cDNA and genomic DNA, and rat c-fos cDNA, respectively. We are grateful to Drs. O. Isozaki and J. Imaki (Nippon Medical College, Tokyo, Japan) for helpful discussions on experiments, Drs. S. Minami and H. Sugihara (Nippon Medical College) for densitometric analysis, and Y. Sato for technical assistance.

\section{References}

1. Rivier, C., J. Rivier, and W. Vale. 1982. Inhibition of adrenocorticotropic hormone secretion in the rat by immunoneutralization of corticotropin-releasing factor. Science (Wash. DC). 218:377-379.

2. Rivier, C. L., and P. M. Plotsky. 1986. Mediation by corticotropin-releasing factor (CRF) or adenohypophyseal hormone secretion. Annu. Rev. Physiol. 48:475-494.

3. Vale, W., C. Rivier, M. R. Brown, J. Spiess, G. Koob, L. Swanson, L. Bilezikjian, F. Bloom, and J. Rivier. 1983. Chemical and biological characterization of corticotropin-releasing factor. Recent Prog. Horm. Res. 39:245-270.

4. Jingami, H., S. Matukura, S. Numa, and H. Imura. 1985. Effects of adrenalectomy and dexamethasone administration on the level of prepro-corticotropinreleasing factor messenger ribonucleic acid (mRNA) in the hypothalamus and adrenocorticotropin/ $\beta$-lipotropin precursor mRNA in the pituitary in rats. Endocrinology. 117:1314-1320.

5. Young, W. S., E. Mezey, and R. E. Siegel. 1986. Quantitative in situ hybridization histochemistry reveals increased levels of corticotropin-releasing factor mRNA after adrenalectomy. Neurosci. Lett. 70:198-203.

6. Imaki, T., J.-L. Nahon, C. Rivier, P. E. Sawchenko, and W. Vale. 1991. Differential regulation of corticotropin-releasing factor mRNA in rat brain regions by glucocorticoids and stress. J. Neurosci. 11:585-599.

7. Lightman, S. L., and W. S. Young III. 1988. Corticotropin-releasing factor, vasopressin and pro-opiomelanocortin mRNA responses to stress and opiates in the rat. J. Physiol. (Lond.) 403:511-523.

8. Sternberg, E. M., W. S. Young III., R. Bernardini, A. Calogero, G. P. Chrousos, P. W. Gold, and R. L. Wilder. 1989. A central nervous system defect in biosynthesis of corticotropin-releasing hormone is associated with susceptibility to streptococcal cell wall-induced arthritis in Lewis rats. Proc. Natl. Acad. Sci. USA. 86:4771-4775.

9. Harbuz, M. S., and S. L. Lightman. 1989. Responses of hypothalamic and pituitary mRNA to physical and psychological stress in the rat. J. Endocrinol. 122:705-711.

10. Adler, K. A., C. M. Smas, and J. A. Majzoub. 1988. Expression and dexamethasone regulation of the human corticotropin-releasing hormone gene in a mouse anterior pituitary cell line. J. Biol. Chem. 263:5846-5852.

11. Van, L. P., D. H. Spengler, and F. Holsboer. 1990. Glucocorticoid repression of 3',5'-cyclic-adenosine monophosphate-dependent human corticotropinreleasing hormone gene promoter activity in a transfected mouse anterior pituitary cell line. Endocrinology. 127:1412-1418.

12. Rosen, L. B., J. A. Majzoub, and G. K. Adler. 1992. Effects of glucocorticoid on corticotropin-releasing hormone gene regulation by second messenger pathways in NPLC and AtT-20 cells. Endocrinology. 130:2237-2244.

13. Blum, M., and J. L. Roberts. 1989. Quantitation of nuclear low-level gene expression in central nervous system using solution hybridization and in situ hybridization. In Gene Probes. P. M. Conn, editor. Academic Press, Inc., San Diego. 293-303.

14. Paek, I., and R. Axel. 1987. Glucocorticoids enhance stability of human growth hormone mRNA. Mol. Cell. Biochem. 7:1496-1507.

15. Carrazana, E. J., K. B. Pasieka, and J. A. Majzoub. 1988. The vasopressin mRNA poly (A) tract is unusually long and increases during stimulation of vasopressin gene expression in vivo. Mol. Cell. Biol. 8:2267-2274.

16. Zingg, H. H., D. L. Lafebvre, and G. Almazan. 1988. Regulation of poly (A) tail size of vasopressin mRNA. J. Biol. Chem. 263:11041-11043.

17. Imaki, T., T. Shibasaki, M. Hotta, and H. Demura. 1992. Early induction of c-fos precedes increased expression of corticotropin-releasing factor mRNA in the paraventricular nucleus after immobilization stress. Endocrinology. 131:240246.

18. Lewin, B. 1980. Gene expression II. In Eukaryotic Chromosomes. B. Lewin, editor. Wiley-Liss, Inc., New York. 728-864.

19. Darnell, J. E., Jr. 1983. The processing of RNA. Sci. Am. 249:90-100.

20. Fremeau, R. T., J. R. Lundblad, Jr., D. B. Pritchett, J. N. Wilcox, and J. L. Roberts. 1986. Regulation of pro-opiomelanocortin gene transcription in individual cell nuclei. Science (Wash. DC). 234:1265-1269.

21. Autelitano, D. L., M. Blum, and J. L. Roberts. 1989. Changes in rat pituitary nuclear and cytoplasmic pro-opiomelanocortin RNAs associated with adrenalectomy and glucocorticoid replacement. Mol. Cell. Endocrinol. 66:171180.

22. Herman, J. P., M. K.-H. Schafer, S. J. Watson, and T. G. Sherman. 1991. In situ hybridization analysis of arginine vasopressin gene transcription using intron-specific probes. Mol. Endocrinol. 5:1447-1456.

23. Priou, A., C. Oliver, and M. Grino. 1993. In situ hybridization of arginine vasopressin (AVP) heteronuclear ribonucleic acid reveals increased AVP gene transcription in the rat hypothalamic paraventricular nucleus in response to emotional stress. Acta Endocrinol. 128:466-472.

24. Herman, J. P., M. K.-H. Schafer, R. C. Thompson, and S. J. Watson. 1992. Rapid regulation of corticotropin-releasing hormone gene transcription in vivo. Mol. Endocrinol. 6:1061-1069.

25. Thompson, R. C., A. F. Seasholtz, and E. Herbert. 1987. The rat corticotropin-releasing hormone gene: sequence and tissue-specific expression. Mol. Endocrinol. 1:363-370.

26. Morgan, J. L., and T. Curran. 1991. Stimulus-transcription coupling in the nervous system: involvement of the inducible proto-oncogenes fos and Jun. Annu. Rev. Neurosci. 14:421-451.

27. Sager, S. M., F. R. Sharp, and T. Curran. 1988. Expression of c-fos protein in brain: metabolic mapping at the cellular level. Science (Wash. DC). 240:13281331.

28. Dragunow, M., and R. Faull. 1989. The use of c-fos as a metabolic marker in neuronal pathway tracing. J. Neurosci. Methods. 29:261-265.

29. Ceccatelli, S., M. J. Vilar, M. Goldstein, and T. Hokfelt. 1989. Expression of c-fos immunoreactivity in transmitter-characterized neurons after stress. Proc. Natl. Acad. Sci. USA. 86:9569-9573.

30. Sharp, F. R., S. M. Sager, K. Hicks, D. Lowenstein, and K. Hisanaga. 1991. c-fos mRNA, fos, and fos-related antigen induction by hypertonic saline and stress. J. Neurosci. 11:2321-2331.

31. Imaki, T., J.-L. Nahon, P. E. Sawchenko, and W. Vale. 1989. Widespread expression of corticotropin-releasing factor messenger RNA and immunoreactivity in the rat olfactory bulb. Brain Res. 496:35-44.

32. Minami, S., K. Kamegai, H. Sugihara, O. Hasegawa, and I. Wakabayashi. 1992. Systemic administration of recombinant human growth hormone induces expression of c-fos gene in the hypothalamic arcuate and periventricular nuclei in hypophysectomized rats. Endocrinology. 131:247-253.

33. Seasholtz, A. F., R. C. Thompson, and J. O. Douglass. 1988. Identification of a cyclic AMP-responsive element in the rat corticotropin-releasing hormone gene. Mol. Endocrinol. 2:1311-1319.

34. Owens, M. J., and C. B. Nemeroff. 1991. Physiology and pharmacology of corticotropin-releasing factor. Pharmacol. Rev. 43:425-435. 
35. Fink, G., I. C. A. F. Robinson, and L. A. Tannahill. 1988. Effects of adrenalectomy and glucocorticoids on the peptides CRF-41, AVP and oxytocin in rat hypophysial portal blood. J. Physiol. 401:329-334.

36. Harbuz, M. S., and S. L. Lightman. 1989. Glucocorticoid inhibition of stress-induced changes in hypothalami corticotrophin-releasing factor messenger RNA and proenkephalin A messenger RNA. Neuropeptides. 14:17-20.

37. Harbuz, M. S., S. A. Nicholson, B. Gillham, and S. L. Lightman. 1990. Stress responsiveness of hypothalamic corticotrophin-releasing factor and pituitary pro-opiomelanocortin mRNAs following high-dose glucocorticoid treatment and withdrawal in the rat. J. Endocrinol. 127:407-415.

38. Covenas, R., M. de Leon, A. Cintra, B. Bjelke, J.-A. Gustafsson, and K. Fuxe. 1993. Coexistence of c-fos and glucocorticoid receptor immunoreactivities in the CRF immunoreactive neurons of the paraventricular hypothalamic nucleus of the rat after acute immobilization stress. Neurosci. Lett. 149:149-152.

39. Lightman, S. L., and W. Scott Young III. 1989. Influence of steroids on the hypothalamic corticotropin-releasing factor and preproenkephalin mRNA responses to stress. Proc. Natl. Acad. Sci. USA. 86:4306-4310.

40. Bacon, E. R., and P. E. Sawchenko. 1993. Adrenalectomy prevents a dynamic stimulatory challenge to parvocellular neurosecretory neurons. Soc. Neurosci. Abstr. 19:760.

41. Emanuel, R. L., D. M. Girard, D. L. Thull, and J. A. Majzoub. 1990. Second messengers involved in the regulation of corticotropin-releasing hormone mRNA and peptide in cultured rat hypothalamic primary cultures. Endocrinology. 126:3016-3021.

42. Adler, G. K., L. B. Rosen, M. J. Fiandaca, and J. A. Majzoub. 1992. Protein kinase-C activation increases the quantity and poly (A) tail length of corticotropin-releasing hormone messenger RNA in NPLC cells. Mol. Endocrinol. 6:476-484.

43. Vamvakopoulos, N. C., and G. P. Chrousos. 1993. Regulated activity of the distal promoter-like element of human corticotropin releasing hormone gene and second structural features of its corresponding transcripts. Mol. Cell Endocrinol. 94:73-78.

44. Vamvakopoulos, N. C., and G. P. Chrousos. 1993. Structural organization of the $5^{\prime}$ flanking region of the human corticotropin-releasing hormone gene. DNA Sequence-J DNA Sequencing and Mapping 4:197-206. 